\title{
Fiber Optic Sensors Materials based Spontaneous Combustion Detection in Goaf Areas
}

\author{
Enji Sun ${ }^{1, a^{*}}$ \\ ${ }^{1}$ Industrial Safety Technology Department, China Academy of Safety Science and Technology, \\ Beijing, China \\ asunej@chinasafety.ac.cn
}

Keywords: Prediction and detection, Fiber optic sensor materials, Spontaneous combustion, Goaf areas, Coal mines.

\begin{abstract}
The main objective of this paper is to provide a possible monitoring system, which includes multiple sensors such as fiber optic temperature sensor, gas sensor and differential absorptive methane optic fiber sensor. Optic fiber sensors offer a number of unique advantages for safety monitoring in explosive and hazardous environment of the underground coal mines. The application potential and future trend of optic fiber sensors for coal mine hazard detection and prevention are discussed. This paper also researches on the prediction methodologies such as spontaneous combustion tendency prediction method, factors judgment prediction, experience statistical prediction method and mathematical models based on coal layer conditions, mining methods, and goaf areas. The combination uses of fiber optic sensors and prediction models are helpful to increase the safety of coal mines.
\end{abstract}

\section{Introduction}

Coal is the essential energy for human beings in the current energy consume structure [1]. China has become the largest consumer of coal in the world and is about to become the largest user of coal derived electricity, generating 1.95 trillion kilowatt hours per year, or $68.7 \%$ of its electricity from coal as of 2006 [2]. The top 10 coal consuming countries consumed $85 \%$ of the world's coal in 2012. Eight of the 10 largest producers are among the top 10 consumers. China is the largest coal consumer, accounting for $49 \%$ of the world's total coal. The next largest, the United States, consumed $11 \%$ of the world's total. China's coal consumption increased by more than 2.3 billion tons over the past 10 years, accounting for $83 \%$ of the global increase in coal consumption [3] as shown in Fig. 1.

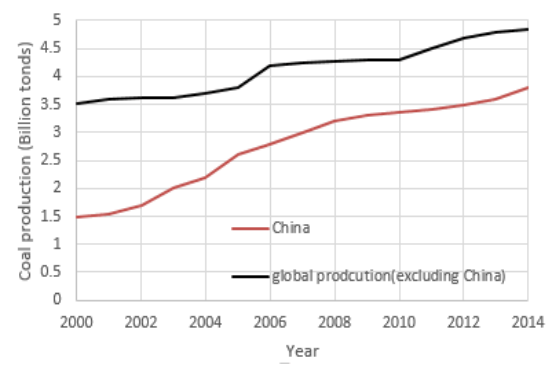

Fig. 1 Coal production in China and the rest of the world.

(Source: U.S. Energy Information Administration, International Energy Statistics)

In the first nine months of 2009, China's coal mines had 11 major accidents with 303 deaths, with gas explosions the leading cause, according to the central government [4]. Most accidents are blamed on failures to follow safety rules, including a lack of required ventilation or fire control equipment [5]. Spontaneous heating and induced fire in coal mines is a major problem and has been a great concern 
both for the industry and researchers worldwide [6]. $51.3 \%$ of the coal mines have positional spontaneous fire hazards in China [7]. The majority of fires existing today in different coalfields are due to spontaneous combustion of coal [8]. In the coal mining industry, most spontaneous combustion fires occur in long wall or gob areas [9]. The incidence of spontaneous combustion fires and the resulting explosion hazard in underground coal mines is expected to increase with the projected increased mining of lower rank coals, deeper mines with more methane, and the growth in the dimensions of long wall panels. It is important to detect the possible spontaneous combustion ahead of the disaster happened in coal mines especially in gob areas [10].

The main objective of this paper is to provide a possible monitoring system, which includes multiple sensors such as fiber optic temperature sensor, gas sensor and differential absorptive methane optic fiber sensor. Optic fiber sensors offer a number of unique advantages for safety monitoring in explosive and hazardous environment of the underground coal mines. The application potential and future trend of optic fiber sensors for coal mine hazard detection and prevention are discussed. This paper also researches on the prediction methodologies such as spontaneous combustion tendency prediction method, factors judgment prediction, experience statistical prediction method and mathematical models based on coal layer conditions, mining methods, and goaf areas. The combination uses of fiber optic sensors and prediction.

\section{The Possible Spontaneous Combustion Prevention and Detection Methods in Goaf}

The width of oxidation heating zone needs to be minimized as much as possible [11]. The traditional linear temperature monitoring system is based on the aero dynamic and electrical science, the errors are relatively high and the monitoring information is limited [12]. The electrical temperate and gas sensors are interfered by the strong electromagnetic in the underground coal mines. Concentrated beam tube sensor detection system and gas chromatograph are common gas analysis instruments and apparatus used in coal mines. Concentrated beam tube sensor detection system is widely used in coal mines in China [13]. The disadvantage of this system is the cost of maintaining the repeated installed sensors is huge. Another disadvantage of this system is the concentrated beam tube is brittle and damaged easily, which is not suitable to be used in a goaf area for a long term online detection. Gas chromatograph has great accurate components analysis. But it requires gathering the sample from the field and analyzes the density of each kind of gases in the lab. It is not easy to be used in a goaf real-time monitoring neither. The electrical equipment is not allowed to be used in a goaf area as the regulations required.

Detection System Structure. Based on the characters and reasons of spontaneous combustion induced fire in a goaf, this detection system used fiber optic temperature sensors and optical fiber gas sensors to detect the temperature and gas component and density in a goaf area for a long term monitor remotely. Optical fiber sensors are anti-electromagnetic interference which is great options for a goaf area monitoring in coal mines. The structure of the fiber optic sensors based spontaneous combustion detection system is shown in Fig. 2.



Fig. 2 The structure of the fiber optic sensors based spontaneous combustion detection system. 
The Fiber Optic Temperature Sensors. This system uses fiber optic temperature sensor to monitor the temperature distribution in the goaf area as shown in Fig. 3. Optical fiber has a high temperature tolerance capability (it can bear over $400^{\circ} \mathrm{C}$ ), corrosion resistance, water resistance and long life characteristics for a variety of complex harmful or harsh environments.

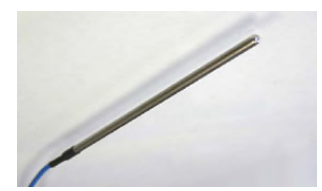

Fig. 3 Fiber optic temperature sensor.

As the input laser travels in the optic fiber, there are three kinds of scattering light known as Rayleigh scattering, Stokes Raman scattering and Anti-Stokes Raman scattering. According to the relationship between Anti-Stokes Raman scattering and temperature in spectroscopy, the optical fiber temperature can be measured in the following method:

$$
T=\frac{h \Delta v}{k \ln \left[1+\frac{\exp \left(\mathrm{h} \frac{h \Delta v}{k T_{0}}\right)-1}{P_{A S}(T)}-P_{A S}\left(T_{0}\right)\right]}
$$

where, PAS(T) is Anti-Stokes Raman scattering light power, $\mathrm{v}$ is the light travel speed in the fiber, $\mathrm{h}, \mathrm{k}$ are Planck coefficient and Boltzmann's constant respectively, $\mathrm{T}$ is absolute temperature, reference temperature.

The standard operating range of this kind of sensors is from $-40^{\circ} \mathrm{C}$ to $+250^{\circ} \mathrm{C}$. Higher temperature ranges up to $350^{\circ} \mathrm{C}$ are available. They are robust designed, good accuracy and low drift and low hysteresis.

Infrared Absorption Optical Fiber Gas Sensors. This system adapts the infrared absorption optical fiber gas sensors to monitor the density of $\mathrm{CO}, \mathrm{CH}_{4}, \mathrm{CO}_{2}, \mathrm{C}_{2} \mathrm{H}_{2}, \mathrm{H}_{2} \mathrm{~S}$, and $\mathrm{O}_{2}$ in a goaf area based on the absorption lines of gases. The Needle-Type optical fiber gas sensors as presented in Fig. 4.

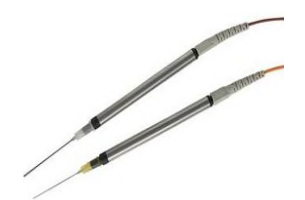

Fig. 4 Needle-type optical fiber gas sensor.

Optical fiber gas sensors are based on gas molecules absorption theory. In this theory, gas molecules can only absorb those photons whose energy level equal to the difference between its two certain energy levels. In that way, different kind of gases molecules absorbs different kinds of frequent photons. Absorption curve expressed the distribution of absorption coefficient. Some common gases in low-loss optical fiber window absorption peak table are shown in Table 1.

Table 1. NIR absorption lines of gases.

\begin{tabular}{|c|c|}
\hline Gas Name & Wavelength/ $\boldsymbol{\mu m}$ \\
\hline $\mathrm{CO}_{2}$ & 1.573 \\
\hline $\mathrm{CO}$ & 1.567 \\
\hline $\mathrm{CH}_{4}$ & 1.665 \\
\hline $\mathrm{C}_{2} \mathrm{H}_{2}$ & 1.53 \\
\hline $\mathrm{H}_{2} \mathrm{~S}$ & 1.578 \\
\hline $\mathrm{O}_{2}$ & 0.761 \\
\hline
\end{tabular}


As the light passes a certain gas, the light transportation way will change due to Reflection, refraction, diffraction of gas molecules. When the laser in wavelength $\lambda$ passes through the detected gases, the outgoing laser density is based on Beer-Lambert (2):

$$
I=I_{0} \exp \left(-\alpha_{\lambda} c L\right)
$$

where, $\mathrm{I}$ is the outgoing light density; $\lambda$ is the input laser wavelength; $\alpha_{\lambda}$ is the absorption coefficient; $C$ is the gas density; $L$ is the gas container length.

$$
c=\frac{1}{\alpha_{\lambda} L} \ln \frac{I_{0}}{I}
$$

The different kind of gases density can be calculated based on the input laser density and the absorption coefficient.

The Spontaneous Combustion Prediction. The possible spontaneous combustion is predicted on the basis of temperature and multiple gases density. The sensors divided into three sections are deployed in the goaf. Each section is $100 \mathrm{~m}$ length. Ten optical fiber sensors are distribution evenly in each section. The faraway section is named section one in the goaf.

$\mathrm{CO}$ density is important in the prediction of spontaneous combustion in a goaf area. The density will change dominantly before and after the spontaneous combustion. The $\mathrm{CO}$ concentration versus temperature is shown in Fig. 5.

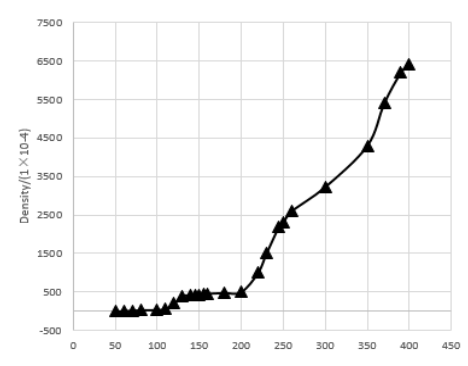

Fig. 5 The density of $\mathrm{CO}$ versus temperature.

The spontaneous combustion induced fire consumes the $\mathrm{O}_{2}$ in different stages. The density of $\mathrm{O}_{2}$ will reflect the possibility of the spontaneous combustion. The $\mathrm{O}_{2}$ density versus temperature is displayed in Fig. 6.

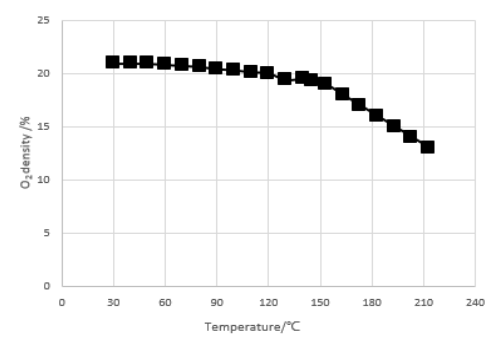

Fig. $6 \mathrm{O}_{2}$ density versus temperature.

The density of $\mathrm{C}_{2} \mathrm{H}_{4}$ varies as the temperature changed during the spontaneous combustion induced fire. The density reaches the peak at $300^{\circ} \mathrm{C}$ and drops after that as shown in Fig. 7. 


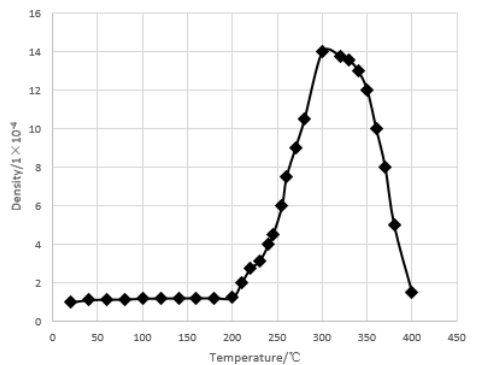

Fig. $7 \mathrm{C}_{2} \mathrm{H}_{4}$ density versus temperature

The temperature changing is a key element in the monitoring of spontaneous combustion. The temperature in the goaf changes differently according to the distance to the seal surface. Section one in in the $300 \mathrm{~m}$ away from the goaf, the temperature is relatively stable around $50^{\circ} \mathrm{C}$. This goaf is well sealed. The air flow does not affect the temperature. The temperature variation in 100 minutes in section one of the goaf area is displayed in Fig. 8.

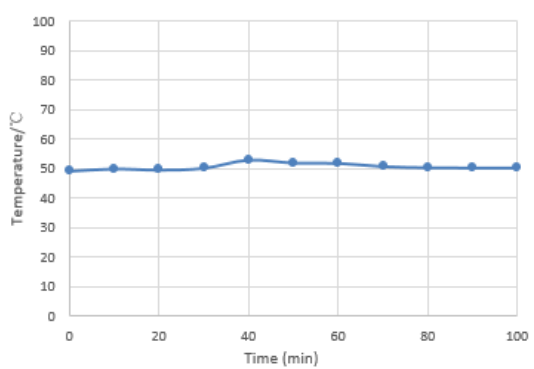

Fig. 8 The temperature variation in 100 minutes in section one of the goaf area.

Section two is $200 \mathrm{~m}$ away from the goaf. The temperature is stable around $50^{\circ} \mathrm{C}$ as shown in Fig. 9 .



Fig. 9 The temperature variation in 100 minutes in section two of the goaf area

Section three is $100 \mathrm{~mm}$ away from the goaf. The temperature changes a lot in 100 minutes. It tends to increase but still in the safe zones as shown in Fig. 10.

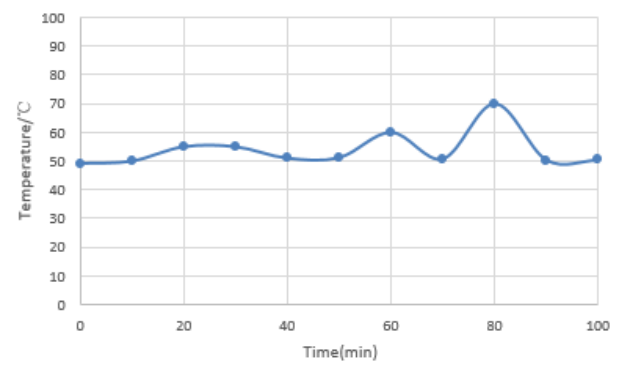

Fig. 10 The temperature variation in 100 minutes in section three of the goaf area. 
Section three is $100 \mathrm{~mm}$ away from the goaf. The temperature changes a lot in 100 minutes. It tends to increase but still in the safe zones as shown in Fig. 11.

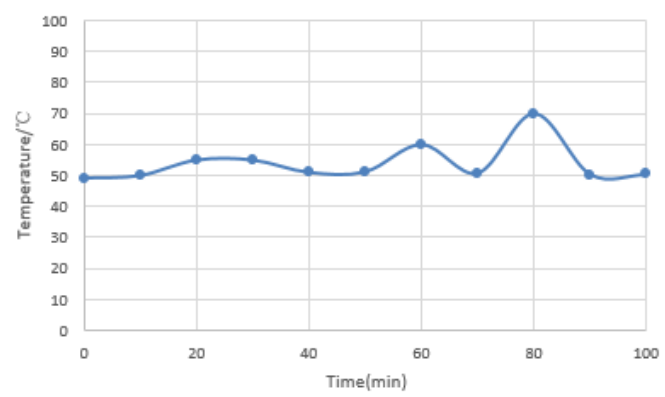

Fig. 11 The temperature variation in 100 minutes in section three of the goaf area.

\section{Conclusion}

The detection of spontaneous combustion is not easy due to the complicated environments in a goaf area of coal mines. This paper analyzed the spontaneous combustion characters and the possible reasons of the induced fire. An optical fiber sensor monitoring system was structured, which is including temperature and multiple gases density optic fiber sensors.

This paper researched on the prediction methodologies such as spontaneous combustion tendency prediction method, factors judgment prediction, experience statistical prediction method and mathematical models based on coal layer conditions, mining methods, and goaf areas. The combination uses of fiber optic sensors and prediction models are helpful to increase the safety of coal mines.

\section{Acknowledgment}

This work was supported by National Natural Science Foundation of China (71373245, 50974109), the basic research funding of China Academy of Safety Science and Technology (2016JBKY07, 2016JBKY01, 2016JBKY18), and National Key Technology R\&D Program of the Ministry of Science and Technology (2015BAK40B01, 2015BAK40B02, 2016YFC0801305).

\section{References}

[1] Y. Mei, Coal in China, Appl. Mech. Mater. 275 (2013) 2784-2787.

[2] E. J. Sun, N. Antonio, Z. X. Li, V. Kecojevic, An integrated information technology assisted driving system to improve mine trucks-related safety, Saf. Sci. 48(10) (2010) 1490-1497.

[3] E. J. Sun, X. K. Zhang, Z. X. Li, The internet of things (IOT) and cloud computing (CC) based tailings dam monitoring and pre-alarm system in mines, Saf. Sci. 50(4) (2012) 811-815.

[4] Y. L. Yang, Z. H. Li, Y. B. Tang, F. J. Gu, H. J. Ji, Z. Liu, Effects of low molecular weight compounds in coal on the characteristics of its spontaneous combustion, Can. J. Chem. Eng. 93(4) (2015) 648-657.

[5] Y. J. Leng, H. Jun, Q. Wu, J. L. Zhu, S. L. Xiao, Research of Coal Temperature Early Warning Method Based on Curve Fitting, In The Proceedings of the Second International Conference on Communications, Signal Processing, and Systems, 2014, 1117-1125, Springer International Publishing.

[6] C. Kuenzer, J. Z. Zhang, A. Tetzlaff, P. Van Dijk, S. Voigt, H. Mehl, W. Wagner, Uncontrolled coal fires and their environmental impacts: Investigating two arid mining regions in north-central China, Appl. Geogr. 27(1) (2007) 42-62. 
[7] B. Taraba, Z. Michalec, Effect of longwall face advance rate on spontaneous heating process in the gob area-CFD modelling, Fuel 90(8) (2011) 2790-2797.

[8] A. C. Ravelo, R. G. Fairbanks, Oxygen isotopic composition of multiple species of planktonic foraminifera: recorders of the modern photic zone temperature gradient, Paleoceanography, 7(6) (1992) $815-831$.

[9] Y. L. Xu, L. Y. Wang, T. X. Chu, D. L. Liang, Suspension mechanism and application of sandsuspended slurry for coalmine fire prevention, Int. J. Min. Sci. Technol. 24(5) (2014) 649-656.

[10]Q. L. Tan, W. D. Zhang, C. Y. Xue, J. J. Xiong, Y. C. Ma, F. Wen, Design of mini-multi-gas monitoring system based on IR absorption, Opt. Laser Technol. 40(5) (2008) 703-710.

[11]M. Li, S. Wang, L. C. He, Development of an analytical method coupling cell membrane chromatography with gas chromatography-mass spectrometry via microextraction by packed sorbent and its application in the screening of volatile active compounds in natural products, $\mathrm{J}$. Chromatography, 974 (2015) 9-16.

[12]M. J. Smith, B. G. Cohen, L. W. Stammerjohn, A. Happ, An investigation of health complaints and job stress in video display operations, Human Factors: J. Hum. Factors Ergonomics Soc. 23(4) (1981) 387-400.

[13]K. Alexander, A model of deep penetration laser welding based on calculation of the keyhole profile, J. Phys. D: Appl. Phys. 27(9) (1994) 1805. 